\title{
Inhibitory effects of Helicobacter pylori infection on murine autoimmune gastritis
}

\author{
M Ohana, K Okazaki, C Oshima, K Kawasaki, T Fukui, H Tamaki, M Matsuura, \\ M Asada, T Nishi, K Úchida, S Uose, H Nakase, M Iwano, Y Matsushima, H Hiai, \\ T Chiba
}

See end of article for authors' affiliations

Correspondence to: K Okazaki, Department of Gastroenterology and Endoscopic Medicine, Faculty of Medicine, Kyoto University, 54

Shogoin-Kawara-cho

Sakyo, Kyoto, 606-8507

Japan;

okak@kuhp.kyoto-u.ac.jp

Accepted for publication 3 March 2003

\begin{abstract}
Background and aim: Long term Helicobacter pylori infection leads to atrophic gastritis but the relation between $\mathrm{H}$ pylori infection and autoimmune related atrophic gastritis (AIG) remains unclear. We studied the effects of $H$ pylori infection on the pathophysiology of AIG in mice.

Materials and methods: $B A L B / c$ nu/nu mice $(n=40)$ with or without $H$ pylori infection received splenocytes from neonatally thymectomised mice to induce AIG. Half of the mice were orally infected with $H$ pylori prior to AIG induction. Histological findings, and local and systemic immune responses were serially evaluated.

Results: Two and six months after transfer, parietal cells in uninfected mice were depleted while those in infected mice were well preserved. The degree of gland atrophy $(p<0.01)$, hyperplasia $(p<0.01)$, gastric $\mathrm{pH}(\mathrm{p}<0.05)$, and serum gastrin levels of infected mice were significantly lower than those of uninfected mice. Serum antiparietal cell antibody levels gradually decreased in infected mice, and were significantly lower than those of uninfected mice at six months $(p<0.05)$. Real time polymerase chain reaction studies revealed significantly higher interleukin $4(p<0.05)$ and transforming growth factor $\beta(p<0.05)$ gene expression in the gastric mucosa in infected mice than in uninfected mice at both two and six months after AIG induction.

Conclusions: $\mathrm{H}$ pylori infection inhibited the development of AIG in mice. Th2-type immune responses and transforming growth factor $\beta$ in the gastric microenvironment might be involved in the inhibitory effects of $H$ pylori infection on the development of AIG, in which Th 1 -type responses have an important role.
\end{abstract}

A toimmune gastritis (AIG) is a typical organ specific autoimmune disease, ${ }^{1}$ producing autoantibodies against some molecules, including $\mathrm{H}^{+} \mathrm{K}^{+}$-ATPase and intrinsic factor. ${ }^{23}$ Histologically, AIG is characterised by a chronic inflammatory infiltration affecting only or predominantly the corpus mucosa and causing loss of parietal and chief cells from the gastric gland. ${ }^{1}$ Patients with AIG often have complications such as gastric cancer, gastric carcinoid tumour, ${ }^{45}$ or pernicious anaemia accompanied by achlorhydria. The prevalence of AIG varies, being more common in Caucasians, particularly Scandinavians, in whom it accounts for up to $5 \%$ of patients with chronic gastritis or $1.9 \%$ of Western populations over the age of 60 years. ${ }^{6}{ }^{7}$ In contrast, AIG is rarely encountered in South America or Asia ${ }^{89}$ where there is a high prevalence of Helicobacter pylori infection. ${ }^{10} 11$

$H$ pylori infection is thought to be involved in the development of chronic atrophic gastritis, peptic ulcer, gastric cancer, and lymphoma. ${ }^{12}{ }^{13}$ In addition, several investigators report that $H$ pylori infection may be involved in the development of AIG because of cross reactivity between $\mathrm{H}$ pylori and components of the gastric mucosa. ${ }^{14-16}$ In contrast, some clinical investigations demonstrated a low prevalence of $H$ pylori infection among AIG patients, suggesting that $H$ pylori infection is not likely to be an aetiological factor in AIG. ${ }^{17-19}$ Thus the relation between $H$ pylori infection and AIG remains controversial.

Experimental AIG can be induced in BALB/c mice by thymectomy three days after birth. Murine AIG shares many pathological and clinical features with human AIG, such as selective loss of parietal cells from the gastric mucosa, lymphocytic infiltration, and production of autoantibodies to parietal cells. ${ }^{2021}$ This animal model is induced by $\mathrm{CD}^{+} \mathrm{T}$ cells $^{2021}$ of the Thl subtype. ${ }^{22}$ It is reproducible by adoptive transfer of effector T cells into syngeneic nude mice, ${ }^{22}{ }^{23}$ resulting in a more uniform disease model than in individually thymectomised mice. In the present study, therefore, to examine whether $H$ pylori infection affects the development of AIG, we used nude mice with or without $H$ pylori infection, transferred with effector T cells to induce AIG.

\section{MATERIALS AND METHODS}

Bacterial strain

$H$ pylori (TN2GF4), isolated from a patient with a duodenal ulcer, was provided by Dr M Nakao (Pharmaceutical Research Division, Takeda Chemical Industries Ltd, Osaka, Japan). It was maintained in blood agar base No 2 with horse serum $(5 \%, \mathrm{vol} / \mathrm{vol})$ containing amphotericin B $(2.5 \mathrm{mg} / \mathrm{l})$, trimethoprim (5 mg/l), polymixin (1250 IU/l), and vancomycin (10 $\mathrm{mg} / \mathrm{l})$. Bacteria for experimental inoculation were grown in Brucella broth supplemented with $2.5 \%$ heat inactivated fetal bovine serum at $37^{\circ} \mathrm{C}$. Sterilised glycerol was added to the cultures at a final concentration of $15 \%$, and cultures were maintained at $-80^{\circ} \mathrm{C}$ until use. ${ }^{24}$

\section{Donor mice and AIG induction}

Pregnant BALB/c mice were purchased from SLC (Shizuoka, Japan) and bred under specific pathogen free conditions. Neonatal thymectomy was performed three days after birth under

Abbreviations: AIG, autoimmune gastritis; ELISA, enzyme linked immunosorbent assay; PBS, phosphate buffered saline; IFN- $\gamma$, interferon $\gamma$ : IL-4, interleukin 4; TGF- $\beta$, transforming growth factor $\beta$; PCR polymerase chain reaction; GAPDH, glyceraldehyde-3- phosphate dehydrogenase. 
ether anaesthesia, as described previously. ${ }^{25}$ Four months after thymectomy, serum antiparietal cell antibody levels were measured using an enzyme linked immunosorbent assay (ELISA). Eight mice with high serum antiparietal cell antibody titres were killed and diagnosed with typical AIG by histological examination. Total lymphocytes were prepared from freshly removed spleens for transfer, as described previously. ${ }^{26}$

\section{Recipient nude mice, $H$ pylori infection, and disease transfer}

BALB/c nu/nu mice were purchased from SLC. Twenty five mice were inoculated with $10^{8} \mathrm{H}$ pylori organisms into the stomach at eight weeks of age using a steel catheter, as previously reported. ${ }^{25}$ Colonisation of bacteria was confirmed by May-Giemsa staining and a whole stomach bacterial culture system, as previously described. ${ }^{24}{ }^{25}$ Briefly, after the stomach was opened along the lesser curvature, the longitudinal half of the stomach was homogenised with physiological saline. An aliquot of dilutions was inoculated onto modified Skirrow's agar and incubated at $37^{\circ} \mathrm{C}$ for four days under microaerobic conditions. The density of infection was estimated by counting the number of colonies per plate and expressed as log colony forming units per gastric wall. Another 25 mice were inoculated with saline as a control AIG group.

Lymphocytes from the removed spleens were intravenously injected ( $1 \times 10^{7}$ per recipient mouse) into these mice three months after inoculation with $H$ pylori or saline. Both groups of mice were isolated from one another and bred under specific pathogen free conditions. Mice were killed before $(n=10)$, two months $(n=20)$, or six months $(n=20)$ after the lymphocyte injections.

Age matched normal nude mice served as normal controls $(\mathrm{n}=5)$. All animal experiments were approved by the Animal Ethics Committee of Kyoto University.

\section{Measurement of gastric $\mathrm{pH}$ and histological examination}

After 24 hours of starvation, mice were killed under ether anaesthesia and their stomachs were rapidly removed. The local $\mathrm{pH}$ in the corpus area of the stomach was measured with pH test paper (Advantac, Tokyo, Japan). The stomachs were fixed in neutral buffered formalin, embedded in paraffin wax, and cut into $4 \mu \mathrm{m}$ thick sections. Sections were stained with haematoxylin-eosin.

The degree of gastritis was determined according to a modification of Sakagami's method using a semiquantitative scoring system. ${ }^{27}$ "Chronic inflammation", characterised by infiltration of mononuclear cells, was graded from 0 to 3 , where $0=$ no increase in inflammatory cells, $\mathrm{l}=$ slight infiltration of the lamina propria by lymphocytes and plasma cells, $2=$ moderately dense infiltration, and $3=$ very dense infiltration. Quantitation of gland atrophy and hyperplasia was evaluated according to a modification of Judd's method. ${ }^{28}$ Briefly, 10 complete longitudinal profiles of gastric units were selected at random from the body of the stomach in each mouse. The numbers of parietal cells (for atrophy) or total gland cells (for hypertrophy) per gastric unit were counted under high magnification. Data were expressed as the average number of cells per section of gastric unit for each animal.

\section{Serological examination}

Serum antiparietal cell antibody levels were measured by ELISA, as described previously. ${ }^{2}$ Briefly, duplicate wells of microtitre plates (Corning Inc., Corning, New York, USA) were incubated with antigens $(100 \mu \mathrm{g} / \mathrm{ml})$, extracts prepared from the normal gastric mucosa, in phosphate buffered saline (PBS) for 24 hours at $4^{\circ} \mathrm{C}$. The wells were blocked with PBS containing $2.5 \%$ non-fat dried milk and then incubated for 24 hours at $4^{\circ} \mathrm{C}$ with serial dilutions of sera. The wells were next incubated with horseradish peroxidase labelled goat antimouse Ig (Cappel, Durham, North Carolina, USA) diluted at a predetermined concentration for 24 hours at $4^{\circ} \mathrm{C}$. After rigorous washing, each well was reacted with a substrate (o-phenylenediamine) solution for 15 minutes. The reaction was terminated with $25 \mu \mathrm{l}$ of $2 \mathrm{M} \mathrm{H}_{2} \mathrm{SO}_{4}$, and absorbency at $490 \mathrm{~nm}$ was determined with an ELISA reader. Serum levels of gastrin were measured by radioimmunoassay ${ }^{29}{ }^{30}$ with a commercially available kit (Gastrin-RIAKIT II; Dinabot, Tokyo, Japan).

\section{Quantitation of mRNA expression (TaqMan real time PCR analysis)}

Total RNA was extracted by the single step guanidium thiocyanate-phenol-chloroform method from the stomachs of five mice in each group. Extracted RNA preparations were reverse transcribed with MultiScribe Reverse Transcriptase (PE Applied Biosystems, Foster City, California, USA). The resultant cDNAs (50 ng/reaction) were analysed for expression of interferon $\gamma$ (IFN- $\gamma)$, interleukin 4 (IL-4), and transforming growth factor $\beta$ (TGF- $\beta$ ) genes by TaqMan polymerase chain reaction (PCR) assay, ${ }^{31}$ using an ABI Prism 7700 sequence detection system (Perkin-Elmer, Foster City, California, USA). Reactions were incubated for two minutes at $50^{\circ} \mathrm{C}$, denatured for 10 minutes at $95^{\circ} \mathrm{C}$, and subjected to 40 two step amplification cycles with annealing/extension at $60^{\circ} \mathrm{C}$ for one minute, followed by denaturation at $95^{\circ} \mathrm{C}$ for 15 seconds. Amplifications used for IFN- $\gamma$, IL- 4 , and TGF- $\beta$ covered base pairs 101-178, 198-269, and 445-530, respectively (numbering starts at the start codon), and were analysed with 6-carboxyfluorescein labelled probes. The oligonucleotides and TaqMan fluorogenic probes were: IFN- $\gamma$ (sense, 5'-CTC TGA GAC AAT GAA CGC TAC ACA CT-3'; antisense, 5'-TGG CAG TAA CAG CCA GAA ACA G- 3'; probe, 5'-CAT CTT GGC TTT GCA GCT TTG CAG CTC TTC CTC ATG-3'); IL-4 (sense, 5'-GGA GCT GCA GAG ACT CTT TCG-3'; antisense, 5'-GGC TTT CCA GGA AGT CTT TCA G-3'; probe, $5^{\prime}$-CTG CAC CAT GAA TGA GTC CAA GTC CAC A-3'); TGF- $\beta$ (sense, 5'-CCT GCA AGA CCA TCG ACA TG-3'; antisense, 5'-CGA GCC TTA GTT TGG ACA GGA T-3'; probe, 5'-AAC GGA AGC GCA TCG AAG CCA TC-3'). All TaqMan PCR data were captured using Sequence Detector Software (PE Applied Biosystems), normalised by dividing copies per nanogram of the target gene by copies per nanogram of a housekeeping gene (glyceraldehyde-3-phosphate dehydrogenase (GAPDH), amplified using TaqMan Rodent GAPDH control reagents; PE Applied Biosystems), and expressed as copies per 1000 copies of GAPDH (mean (SEM)).

\section{Immunohistochemistry}

Immunohistochemical staining was performed on freshly frozen sections using the avidin- biotin immunoperoxidase method. Briefly, freshly frozen sections were fixed in acetone for 10 minutes, rinsed in PBS ( $\mathrm{pH} 7.2$ ), and incubated with the appropriate blocking agent for 20 minutes. Biotin conjugated goat antimouse B220, CD4, and CD8 (Pharmingen, San Diego, California, USA) monoclonal antibodies were applied to the sections for two hours. Sections were washed with cold PBS for 30 minutes and incubated with $\mathrm{ABC}$ (Vector Laboratories, Inc., Burlingame, California, USA) for 30 minutes according to the manufacturer's instructions. After washing with PBS, sections were reacted with a fresh mixture of $0.05 \% 3,3^{\prime}$ diaminobenzidine, and $0.005 \% \mathrm{H}_{2} \mathrm{O}_{2}$ in Tris buffer $(0.05 \mathrm{M}, \mathrm{pH}$ 7.6) for five minutes and washed with distilled water. Controls were incubated with normal goat serum (Cappel Laboratories, Cochranville, Pennsylvania, USA) instead of the monoclonal antibodies. These control samples produced negative results.

\section{Statistical analysis}

All results are expressed as means (SEM) for each sample. Differences in histopathological scores between control and 


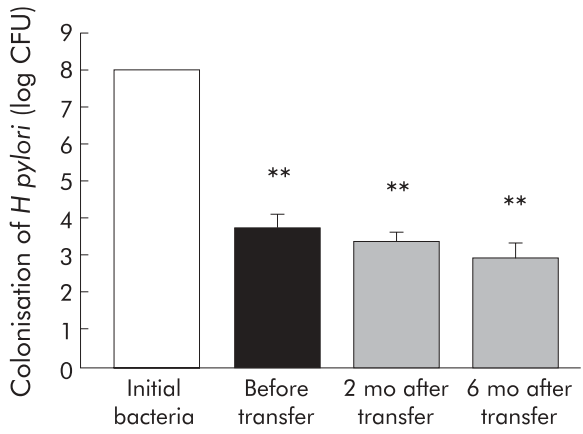

Figure 1 Colonisation of Helicobacter pylori in the gastric mucosa of $\mathrm{BALB} / \mathrm{c}$ nu/nu mice. The number of $\mathrm{H}$ pylori in the gastric mucosa was evaluated using a whole stomach culture system. Data are expressed as mean (SEM) log colony forming units (CFU) for the initial number of $\mathrm{H}$ pylori inoculated into each mouse, for the number of $\mathrm{H}$ pylori three months after inoculation (before induction of autoimmune gastritis (AIG)), and for the number of $\mathrm{H}$ pylori two (2 $\mathrm{mo})$ or six $(6 \mathrm{mo})$ months after induction of AIG. * * Significantly different compared with initial number of $H$ pylori $(p<0.01)$.

infected mice were analysed using the Mann- Whitney U test. Differences in cell number, gastric $\mathrm{pH}$, serum antiparietal cell antibody levels, serum gastrin levels, and quantitative cytokine mRNA expression were analysed using Wilcoxon's $t$ test. A two tailed p value of less than 0.05 was used to indicate statistical significance.

\section{RESULTS}

\section{Bacterial colonisation}

Three months after inoculation of nude mice with $H$ pylori persistent colonisation was confirmed using a whole stomach bacterial culture system, although the number of bacteria was lower than that initially inoculated. Colonisation persisted even at two and six months after transfer of AIG although levels tended to decrease over time (fig 1). We also inoculated other nude mice in which splenocytes from AIG mice were transferred three months before infection, to evaluate the effects of $H$ pylori infection on established AIG. Colonisation was not detected however in any mouse using the culture system (data not shown).

\section{Evaluation of gastritis}

Three months after inoculation, there was no apparent gastritis in saline or $H$ pylori inoculated BALB/c nu/nu mice (fig $2 \mathrm{~A}$, 2B) although the whole stomach bacterial culture from $H$ pylori inoculated BALB/c nu/nu mice revealed persistent colonisation of $H$ pylori (fig 1 ).

Two months after transfer of splenic lymphocytes from neonatal thymectomised mice, histological findings of the stomachs of uninfected mice were typical of AIG, showing loss of parietal cells, proliferation of pit cells, and moderate to severe lymphocyte infiltration (fig 2C). In contrast with human AIG, the mucosa in murine AIG was hypertrophic with proliferation of pit cells following gland atrophy, and depletion of parietal and zymogenic cells. In contrast, histological findings of infected mice varied in the degree of atrophic and hyperplastic changes; parietal cells were relatively preserved, and the hyperplastic change was milder in $H$ pylori infected mice (fig 2D). Although there was no significant difference in chronic inflammation scores of the gastric mucosa between infected and uninfected mice $(2.40(0.16) v 2.70(0.15))$ (fig $3 \mathrm{~A})$, the average number of parietal cells in infected mice was significantly greater than that in uninfected mice $(7.80$ (1.67) $v 2.30(0.58) ; \mathrm{p}<0.01)$ (fig 3B), and the total number of cells per gastric unit in infected mice was significantly lower than that in uninfected mice $(68.8$ (7.04) $v 101.7$ (6.23); $\mathrm{p}<0.01)$ (fig 3C).
Six months after lymphocyte transfer, all 10 uninfected mice developed typical AIG with loss of parietal cells, proliferation of pit cells, and moderate to severe lymphocyte infiltration (fig 2E). In contrast, parietal cells were relatively preserved in $H$ pylori infected mice at two months (figs $2 \mathrm{~F}$ ). Although there was no significant difference in chronic inflammation scores of the gastric mucosa between infected and uninfected mice $(2.40(0.22) v 2.70(0.15))$ (fig 3A), the average number of parietal cells in infected mice was significantly greater than that in uninfected mice $(8.60(1.38) v 2.44$ (0.71); $\mathrm{p}<0.01)$ (fig 3B), and the total number of cells per gastric unit in infected mice was significantly lower than that in uninfected mice (72.30 (7.21) v 102.30 (5.88); p<0.01) (fig $3 \mathrm{C})$.

Because there was considerable variation in the degree of gland atrophy and hyperplasia in $H$ pylori infected mice, we evaluated bacterial colonisation in the stomach of each infected and lymphocyte transferred mouse using the culture system. There was no difference in mucosal colonisation of $H$ pylori between mice with marked gastric hyperplasia $(\mathrm{n}=3)$ and mice with minimal hyperplasia $(\mathrm{n}=3)$ at either two or six months after disease transfer (data not shown).

\section{Gastric $\mathrm{pH}$ and serum gastrin levels}

At two and six months after disease transfer, gastric $\mathrm{pH}$ was significantly elevated compared with control mice, irrespective of $H$ pylori infection $(\mathrm{p}<0.05)$. Gastric $\mathrm{pH}$ in infected mice however was significantly lower than that in uninfected mice two months after AIG induction (4.80 (0.63) v 6.45 (0.29); $\mathrm{p}<0.05$ ) (fig 4 ). Similarly, gastric $\mathrm{pH}$ in infected mice was significantly lower than that in uninfected mice six months after induction of AIG $(4.80(0.63) v 7.13(0.25)$; $<<0.01)$ (fig 4).

Serum gastrin levels significantly increased to 198.0 (35.3) $\mathrm{pg} / \mathrm{ml}$ in uninfected mice two months after transfer compared with control mice $(p<0.01)$. This increase is a characteristic feature of murine AIG but serum gastrin levels in infected mice tended to be lower than those in uninfected mice ( 108.8 (30.3) $\mathrm{pg} / \mathrm{ml} ; \mathrm{p}=0.07$ ) (fig 5). Six months after transfer, serum gastrin levels increased markedly to $322.5(52.0) \mathrm{pg} / \mathrm{ml}$ in uninfected mice $(\mathrm{p}<0.01)$. The increased serum gastrin levels in transferred mice, however, were significantly decreased by $H$ pylori infection (144.8 (36.3) pg/ml $v$ uninfected mice; $\mathrm{p}<0.05$ ) (fig 5).

\section{Serial changes in antiparietal cell antibody titres}

Serum antiparietal cell antibody levels in mice were serially evaluated using ELISA. All mice had increased serum antiparietal cell antibody levels at two months after transfer, irrespective of $H$ pylori infection. Uninfected mice maintained high serum antibody titres throughout the experiment without significant changes. Specific absorbance antiparietal cell antibody levels were $0.709(0.044)$ at two months after transfer, $0.710(0.039)$ at four months, and $0.731(0.033)$ at six months. In contrast, serum antiparietal cell antibody levels in infected mice decreased significantly at four and six months after transfer. Specific absorbance levels were $0.804(0.029)$ at two months, $0.633(0.044)$ at four months $(\mathrm{p}<0.05 v$ two months), and $0.593(0.062)$ at six months $(\mathrm{p}<0.05 v$ two months). Serum antibody levels in infected mice were significantly lower than in uninfected mice at six months after transfer $(\mathrm{p}<0.05)$ (fig 6).

\section{Cytokine messages in the gastric mucoso}

Cytokine mRNA profiles in the gastric mucosa were determined by TaqMan real time PCR. IFN- $\gamma$ was upregulated by AIG transfer at both two and six months compared with normal mice. Two months after transfer, relative IFN- $\gamma$ gene expression levels in the $H$ pylori infected group tended to be higher than those in the uninfected group (26.7 (14.1) $v 15.0$ (3.1) copies/1000 copies of GAPDH) although this was not 

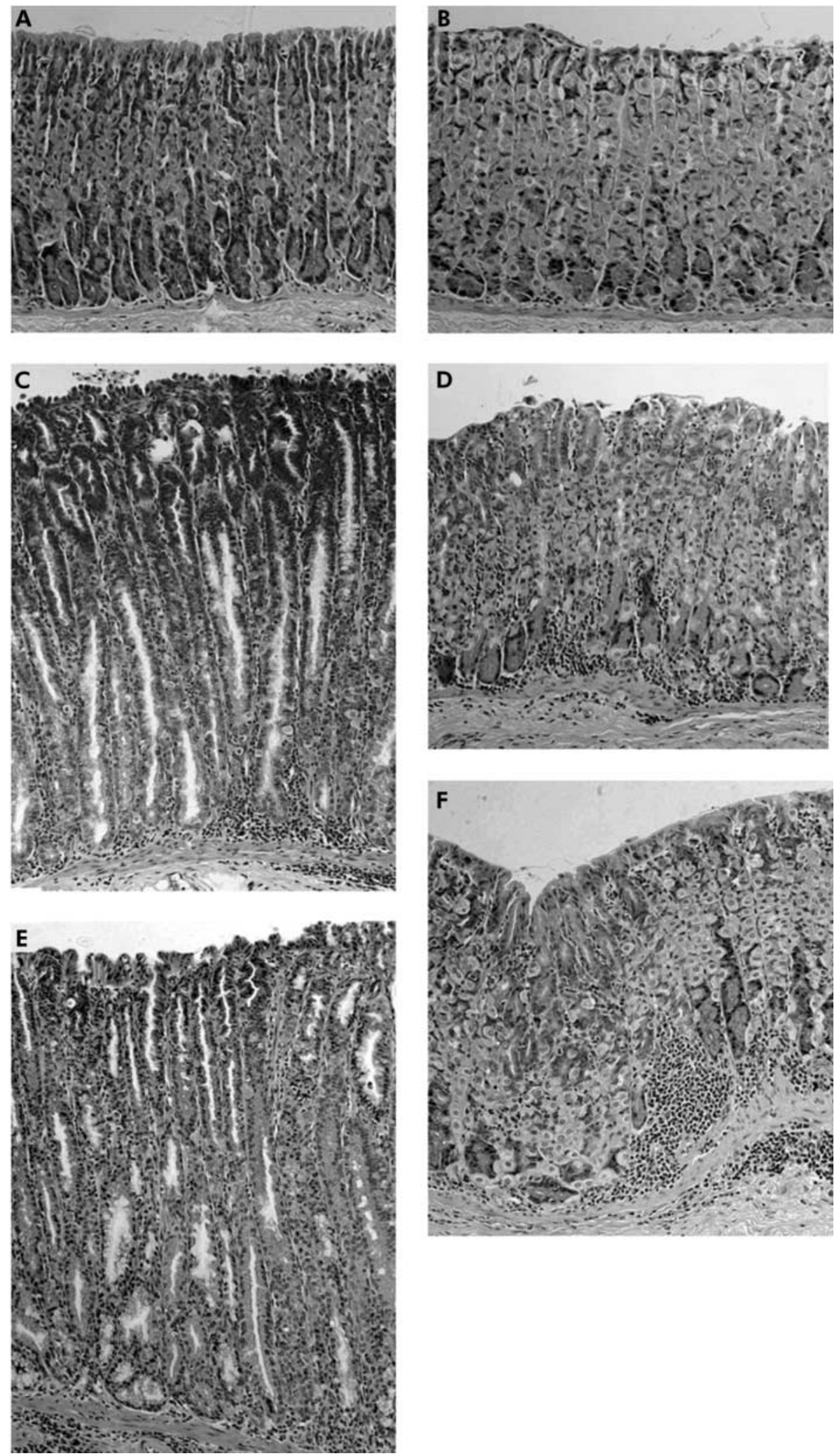

Figure 2 Histopathological findings of the stomach of $B A L B / c$ nu/nu mice with $(C-F)$ or without $(A, B)$ autoimmune gastritis (AIG) transfer (haematoxylin-eosin stain, original magnification $\times 100$ ). Gastric tissue from BALB/c nu/nu mouse was inoculated with saline $(A)$ or Helicobacter pylori (B) three months previously. There was no apparent gastritis in saline or $\mathrm{H}$ pylori inoculated $\mathrm{BALB} / \mathrm{c}$ nu/nu mice. (C) Two months after transfer of splenic lymphocytes from neonatal thymectomised mice, histological findings of the stomachs of uninfected mice were typical of AIG, showing loss of parietal cells, proliferation of pit cells, and moderate to severe lymphocyte infiltration. (D) In contrast, parietal cells were relatively preserved, and the hyperplastic changes were milder in $\mathrm{H}$ pylori infected mice. (E) Six months after transfer, all 10 uninfected mice developed typical AIG with loss of parietal and chief cells, proliferation of pit cells, and moderate to severe lymphocyte infiltration. (F) In contrast, parietal cells were relatively preserved, and the hyperplastic changes were milder in $\mathrm{H}$ pylori infected mice at six months.

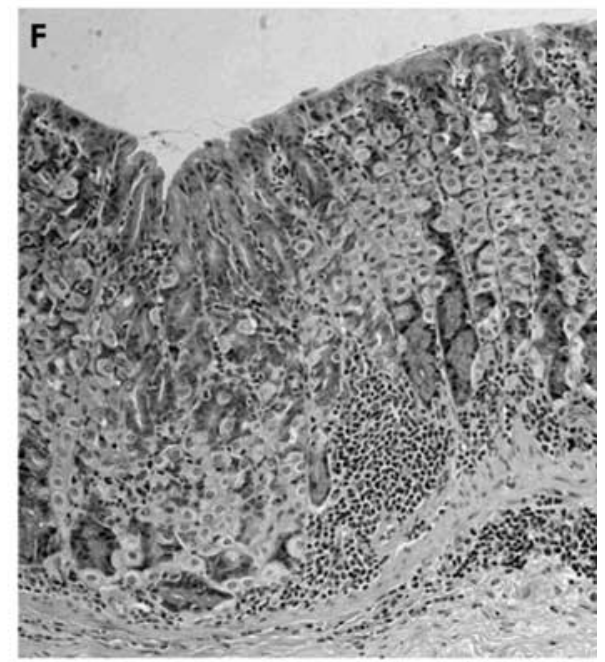

significant. Six months after transfer there was no difference in relative IFN- $\gamma$ gene expression between infected and uninfected mice (16.7 (2.3) v 16.8 (4.6) copies/1000 copies of GAPDH) (fig 7A). IL-4 was also upregulated by AIG transfer at both two and six months compared with control mice. IL-4 gene expression levels in infected mice were significantly higher than those in uninfected mice at both two month $(25.7$ (8.2) $v 3.6(0.7)$ copies/1000 copies of GAPDH; $\mathrm{p}<0.01)$ and six months $(5.2(1.3) \vee 2.2(0.6)$ copies/1000 copies of GAPDH; $\mathrm{p}<0.05$ ) (fig 7B). TGF- $\beta$ was constitutively expressed in the gastric mucosa, and significantly upregulated in infected mice compared with uninfected mice at both two months (245.5 (87.3) v 71.6 (18.9) copies/1000 copies of GAPDH; $<<0.05)$ and six months $(212.0(69.0) v 86.5$ (15.1) copies/1000 copies of GAPDH; $\mathrm{p}<0.05)$ after disease transfer (fig 7C). 

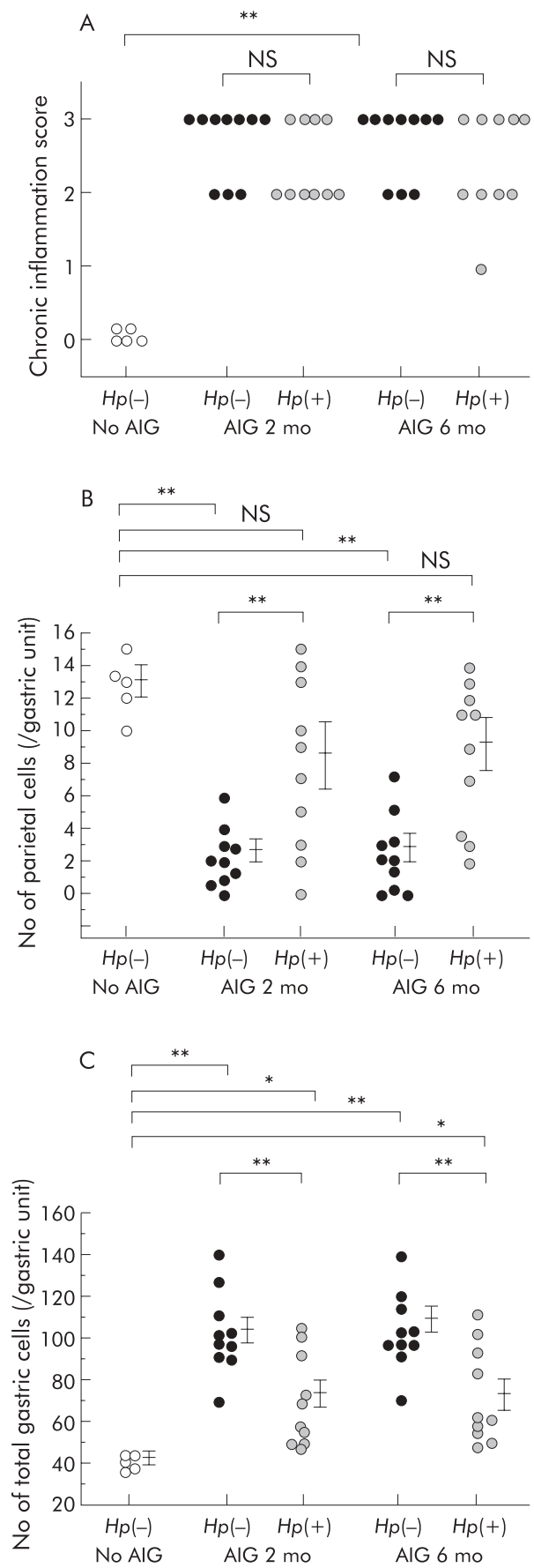

Figure 3 Effects of Helicobacter pylori infection on inflammation, gland atrophy, and hyperplasia in BALB/c nu/nu mice with autoimmune gastritis (AIG) transfer. (A) There was no significant difference in chronic inflammation scores of the gastric mucosa between $\mathrm{H}$ pylori infected and uninfected mice either two $(2 \mathrm{mo})$ or six $(6 \mathrm{mo})$ months after induction of AIG. (B) The number of parietal cells per gastric unit was significantly greater in $\mathrm{H}$ pylori infected mice compared with uninfected mice at both two and six months after induction of AIG. (C) The total number of cells per gastric unit was significantly smaller in $\mathrm{H}$ pylori infected mice compared with uninfected mice at both two and six months after disease transfer. ${ }^{*} p<0.05,{ }^{* *} p<0.01$

\section{Immunohistochemistry}

Histological findings indicated non-destructive gastritis in infected mice and destructive gastritis in uninfected mice although there was no difference in chronic inflammatory scores. The major phenotype of the infiltrating cells in the body mucosa was $\mathrm{CD} 4$ positive-CD8 negative in both

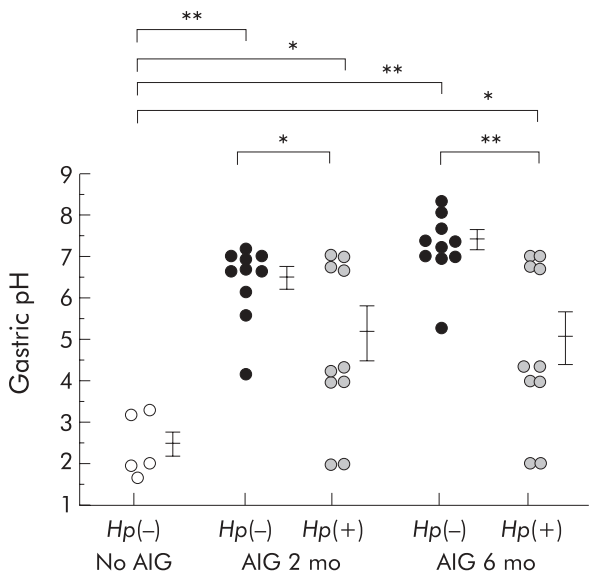

Figure 4 Effects of Helicobacter pylori infection on gastric $\mathrm{pH}$ in autoimmune gastritis (AIG) transferred BALB/c nu/nu mice. At two 12 $\mathrm{mo})$ and six $(6 \mathrm{mo})$ months after AIG induction, gastric $\mathrm{pH}$ was significantly elevated compared with control mice, irrespective of $H$ pylori infection. Gastric pH in infected mice however was significantly lower than in uninfected mice. ${ }^{*} p<0.05,{ }^{* *} p<0.01$

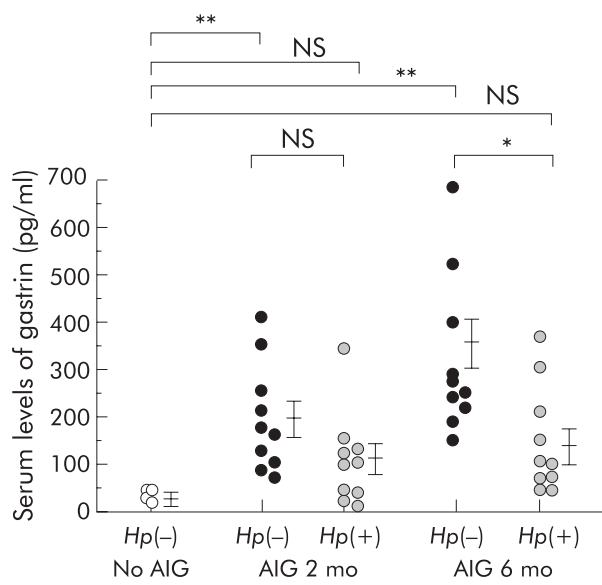

Figure 5 Effects of Helicobacter pylori infection on serum gastrin levels in autoimmune gastritis (AIG) transferred BALB/c nu/nu mice. Serum gastrin levels increased significantly in uninfected mice two months $(2 \mathrm{mo})$ after transfer. Serum gastrin levels in infected mice tended to be lower than those in uninfected mice $(p=0.07)$. Six months $(6 \mathrm{mo})$ after transfer, serum gastrin levels markedly increased in uninfected mice. The increased serum gastrin levels in lymphocyte transferred mice however were significantly decreased by $\mathrm{H}$ pylori infection. ${ }^{*} p<0.05,{ }^{* *} p<0.01$.

uninfected and infected transferred mice. In contrast, clusters of B220 positive cells were partially observed in infected mice but not in uninfected mice (fig 8).

\section{DISCUSSION}

Although mucosal atrophy is a characteristic feature of both $H$ pylori induced gastritis and AIG, the relation between $H$ pylori infection and AIG is controversial. Several investigators have suggested that $H$ pylori infection initiates an autoimmune process in the gastric mucosa, especially in parietal cell ${ }^{32}$ and, moreover, that $\mathrm{H}$ pylori eradication induces cure of $\mathrm{AIG}^{33}$ Indeed, patients with chronic $H$ pylori gastritis with body mucosal atrophy have serum autoantibodies that react with gastric $\mathrm{H}^{+} \mathrm{K}^{+}$-ATPase. ${ }^{14} \mathrm{H}$ pylori lipopolysaccharide contains Lewis y and/or Lewis $\mathrm{x}$ antigens similar to those expressed by human gastric epithelial cells, especially in the glycosylated $\mathrm{H}^{+} \mathrm{K}^{+}$-ATPase beta subunit. ${ }^{14}{ }^{34}{ }^{35}$ The hypothesis that $H$ pylori induces autoantibodies through common expression of Lewis antigens seems unlikely however because binding of serum 


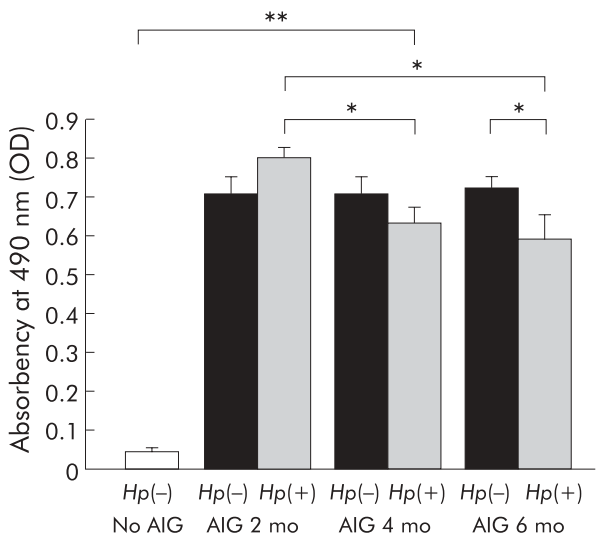

Figure 6 Effects of Helicobacter pylori infection on antiparietal cell antibody titres in autoimmune gastritis (AIG) transferred BALB/C nu/nu mice. All mice had increased serum antiparietal antibody levels two months $(2 \mathrm{mo})$ after transfer, irrespective of $H$ pylori infection. Uninfected mice maintained high serum antiparietal cell antibody levels throughout the experiments without significant changes. In contrast, serum antiparietal cell antibody levels in infected mice significantly decreased at four $(4 \mathrm{mo})$ and six $(6 \mathrm{mo})$ months after disease transfer. Serum antibody levels in infected mice were significantly lower than those in uninfected mice at six months. Parietal cell antibody titre was determined by measuring absorbency at $490 \mathrm{~nm}$ using an ELISA reader. Data are expressed as means (SEM). ${ }^{*} p<0.05,{ }^{* *} p<0.01$.

anticanalicular autoantibodies is not decreased by preabsorption with $H$ pylori. ${ }^{14}{ }^{36}{ }^{37}$ In contrast, several epidemiological and clinical studies suggest that $H$ pylori infection is not likely to be involved in AIG because the prevalence of $H$ pylori infection in patients with pernicious anaemia is extremely low. ${ }^{17-19} 38$ It is also worth noting that AIG is rare in Asia and South America where the prevalence of $H$ pylori infection is high. $^{8-11}$

Genetic background may be a factor affecting the development of $\mathrm{AIG}{ }^{8}$ and might cause geographic diversity of the prevalence of AIG. In mice, the incidence of experimental AIG depends on the mouse strain, suggesting the importance of genetic factors. ${ }^{39}{ }^{40}$ In this study, we examined whether $\mathrm{H}$ pylori infection affects the development of AIG using a genetically identical host.

A possible reason for the low prevalence of $H$ pylori infection in patients with pernicious anaemia is that $H$ pylori cannot colonise in severely atrophic gastric mucosa with AIG. ${ }^{41}{ }^{42}$ Supporting this idea, $H$ pylori did not colonise the murine gastric mucosa with established AIG. In humans however progression of AIG is very slow, spanning 20-30 years, and median age at diagnosis is 60 years. ${ }^{7}$ Because most cases of $H$ pylori infection are established in childhood, it is natural that a longstanding $H$ pylori infection precedes the onset of AIG. In this study therefore we inoculated nude mice with $H$ pylori three months before transfer of lymphocytes from AIG mice.

Human AIG is characterised by chronic infiltration of inflammatory cells within the fundic mucosa, loss of parietal cells from the fundic gland, and the presence of circulating autoantibodies to parietal cells. ${ }^{1}$ Murine experimental AIG can be induced by thymectomising BALB/C mice on the third postnatal day. It shares common pathological and clinical features with human AIG, including lymphocytic infiltration and selective loss of parietal cells from the fundic mucosa, production of autoantibodies to parietal cells, elevated gastric $\mathrm{pH}$, and hypergastrinaemia. ${ }^{20}{ }^{21}$ Murine AIG is induced by $\mathrm{CD} 4^{+}$Thl cells, recognising the alpha or beta subunit of $\mathrm{H}^{+} \mathrm{K}^{+}$-ATPase of parietal cells, and can be induced in syngeneic nude mice by adoptive cell transfer. ${ }^{22}{ }^{43} \mathrm{BALB} / \mathrm{C}$ mice are relatively resistant to the development of chronic gastritis following infection with $H$ pylori ${ }^{27}{ }^{44}$ In the present study however using this nude
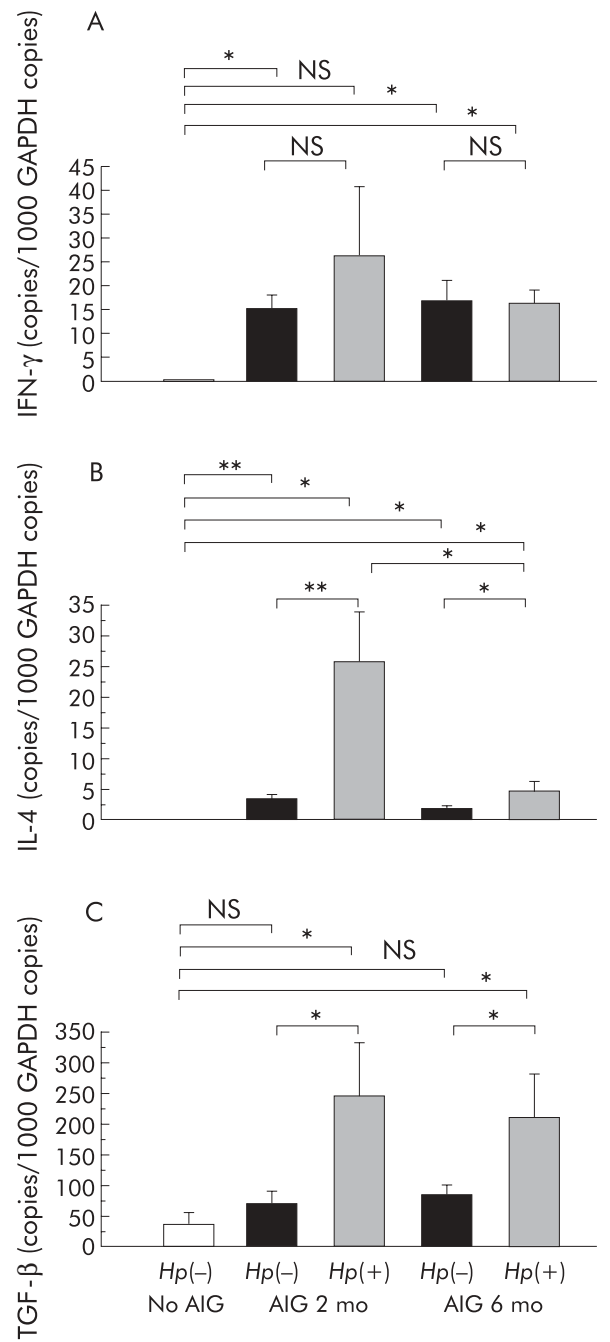

Figure 7 Effects of Helicobacter pylori infection on mucosal cytokine messages in autoimmune gastritis (AIG) transferred BALB/c nu/nu mice. The cytokine mRNA profiles in the gastric mucosa were determined using real time polymerase chain reaction. Data are expressed as means (SEM) for copies of mRNA/1000 copies of glyceraldehyde-3-phosphate dehydrogenase (GAPDH). Interferon $\gamma$ (IFN- $\gamma$ ) was upregulated by AIG transfer at both two and six months compared with normal mice. There was no significant difference in relative IFN- $\gamma$ gene expression between infected and uninfected mice at either two or six months after disease transfer (A). Interleukin 4 (IL-4) was also upregulated by AIG transfer at both two and six months compared with control mice. IL- 4 gene expression levels in infected mice were significantly higher than those in uninfected mice both at two and six months after disease transfer (B). Transforming growth factor $\beta$ (TGF- $\beta$ ) was constitutively expressed in the gastric mucosa, and significantly higher in infected mice than in uninfected mice both at two and six months after disease transfer (C). ${ }^{*} p<0.05$, ${ }^{* *} p<0.01$.

mouse model, we provided compelling evidence that $H$ pylori infection inhibits the development of characteristic features of murine AIG, including destruction of parietal cells, elevation of gastric $\mathrm{pH}$, production of antiparietal cell antibodies, and increase in serum gastrin.

This animal model clarifies the effects of $H$ pylori infection on progression of AIG rather than the role of $H$ pylori infection in the initiation of AIG because the lymphocytes transferred to $\mathrm{nu} / \mathrm{nu}$ mice have already been activated in mice with established AIG. Our findings are however compatible with a previous report that concomitant $H$ pylori infection might be protective before the autoimmune lesion develops into total gastric atrophy. ${ }^{25}$ 

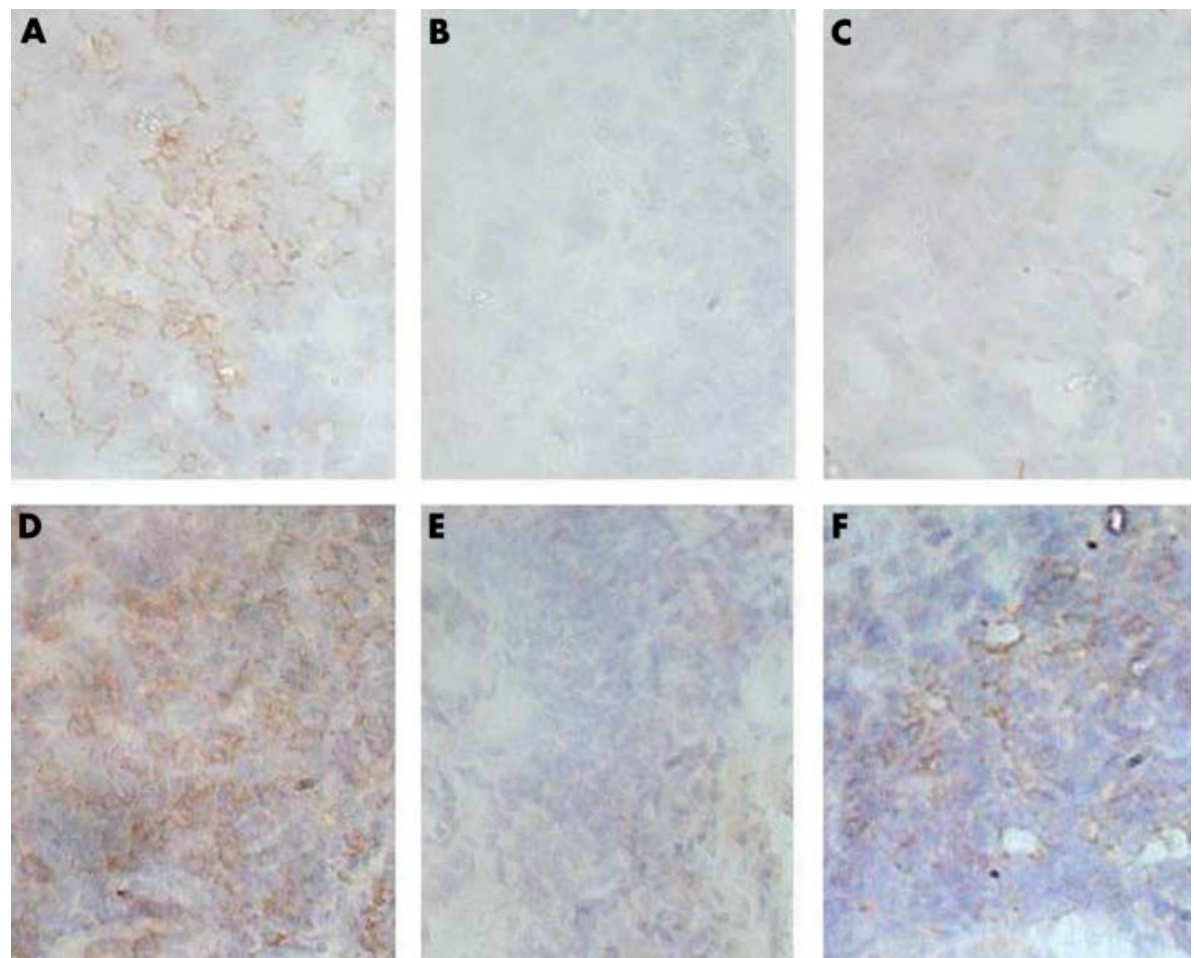

Figure 8 Immunohistochemical staining of gastric mucosa of uninfected (A-C) or Helicobacter pylori infected (D-F) autoimmune gastritis (AIG) transferred mice (original magnification $\times 400$ ). Each section was incubated with antimouse CD4 (A, D), CD8 (B, E), or B220 (C, F) monoclonal antibody. The major phenotype of the lymphocytes infiltrating the gastric mucosa was CD4 positive-CD8 negative in both uninfected and $H$ pylori infected mice (A, B, D, E). In contrast, B220 positive cells partially infiltrated the gastric mucosa of infected mice while no cells stained for B220 in the gastric mucosa of uninfected mice (C, F).

In this experiment, $\mathrm{BALB} / \mathrm{c}$ nu/nu mice did not develop gastritis due to $H$ pylori infection because they had no $\mathrm{T}$ lymphocytes which cause chronic inflammation in gastric mucosa infected with $H$ pylori. In contrast, mice that received splenocytes from AIG mice can respond to $H$ pylori because the lymphocytes transferred from the donor mice can be stimulated by $H$ pylori in recipient mice. Indeed, serum anti-H pylori antibody levels were elevated in infected AIG transferred mice whereas there was no elevation of serum anti- $H$ pylori antibodies in infected non-transferred nu/nu mice (data not shown).

In the present study, in addition to IFN- $\gamma$ expression (a Thl response marker), there was upregulation of gastric IL-4 expression (a Th2 subtype marker) and TGF- $\beta$ by $H$ pylori infection in AIG mice. Although Thl cells are predominant not only in $\mathrm{AIG}^{22}{ }^{45}{ }^{46}$ but also in H pylori induced gastritis, ${ }^{47-52} \mathrm{sev}$ eral lines of evidence suggest that Th2 cytokines also have an important role in the pathophysiology of $H$ pylori induced gastritis..$^{2753} \mathrm{Thl}$ and Th2 responses are mutually exclusive. ${ }^{55}$ Thus it is reasonable to speculate that preservation of parietal cells in H pylori infected AIG mice is due to suppression of Thl function by activation of Th2 responses by $H$ pylori infection, causing inhibition of parietal cell specific Thl effectors. In previous reports, lymphoid follicles, including B cells, formed in the gastric mucosa of neonatally thymectomised mice infected with $H$ pylori and were accompanied by local upregulation of a Th2-type cytokine, IL-4. ${ }^{25}{ }^{56}$ The present study also demonstrates that a population of $\mathrm{B}$ cells emerges in the inflamed gastric mucosa of mice infected with $H$ pylori (fig 8). Our result is similar to a recent finding that progression of $H$ pylori induced gastritis and gastric atrophy mediated by ThI cells is modulated by concurrent parasite infection, which induces Th2 responses. ${ }^{57}$

In the present study, $H$ pylori infection upregulated TGF- $\beta$ expression in the gastric mucosa of AIG mice. TGF- $\beta$ has a wide variety of biological actions ${ }^{58}$ including anti-inflammatory effects. ${ }^{59} 60 \mathrm{TGF}-\beta$ is involved in active suppression as a
Th3 cytokine, ${ }^{61}$ and inhibits Thl responses such as IL-12 induced $\mathrm{T}$ and $\mathrm{NK}$ cell proliferation, or IFN- $\gamma$ production. ${ }^{62-66}$ Indeed, systemic administration of TGF- $\beta$ prevents Thl cell mediated autoimmune diseases. ${ }^{67-69}$

Supporting our data, Lindholm et al reported that the numbers of TGF- $\beta$ specific intraepithelial and lamina propria cells in gastric biopsy samples were higher in $H$ pylori infected than in uninfected subjects. ${ }^{70}$ Lymphocytes that express cell surface bound TGF- $\beta$, rather than secreted TGF- $\beta$, mediate suppression of $\mathrm{CD} 4^{+} \mathrm{CD} 25^{-} \mathrm{T}$ cells, which are considered to be effector cells in AIG. ${ }^{21}{ }^{71}$ Although the source of TGF- $\beta$ was not specified in this study, upregulation of TGF- $\beta$ in the gastric mucosa by $H$ pylori infection might have an important role in the prevention of the development of AIG.

In conclusion, our data support the hypothesis that $H$ pylori infection suppresses the development of AIG. This may explain why the number of AIG patients is low in countries such as Japan where the prevalence of $H$ pylori infection is very high, although one must also consider differences between human AIG and the murine model.

\section{ACKNOWLEDGEMENTS}

This study was supported by a Grant-in-Aid for Scientific Research(C) of the Ministry of Culture and Science of Japan (14570463), a Grantin-Aid for "Research for the Future" Program from the Japan Society for the Promotion of Science (JSPS-RFTF97100201), Supporting Research Funds from the Japanese Foundation for Research and Promotion of Endoscopy (JFE-2001), and the Shimidzu Immunology Foundation, 2000

\section{Authors' affiliations}

M Ohana, K Okazaki, C Oshima, K Kawasaki, T Fukui, H Tamaki, M Matsuura, M Asada, T Nishi, K Uchida, S Uose, H Nakase, M Iwano, Y Matsushima, T Chiba, Department of Gastroenterology and Endoscopic Medicine, Kyoto University, Sakyo, Kyoto, 606-8507 Japan 
H Hiai, Department of Pathology, Kyoto University, Sakyo, Kyoto, 606-8507 Japan

\section{REFERENCES}

1 Strickland $\mathbf{R}$, Mackay I. A reappraisal of the nature and significance of chronic atrophic gastritis. Dig Dis Sci 1973;18:426-40.

2 Mori Y, Fukuma K, Adachi Y, et al. Parietal cell autoantigens involved in neonatal thymectomy-induced murine autoimmune gastritis. Studies using monoclonal autoantibodies. Gastroenterology 1989;97:364-75.

3 Jones CM, Callaghan JM, Gleeson PA, et al. The parietal cell autoantigens recognized in neonatal thymectomy-induced murine gastritis are the alpha and beta subunits of the gastric proton pump. Gastroenterology 1991;101:287-94.

4 Mosbech J, Vidabaek A. Mortality from the risk of gastric carcinoma among patients with pernicious anemia. BM 1950;2:390-4.

5 Stockbrugger RW, Menon GG, Beilby JO, et al. Gastroscopic screening in 80 patients with pernicious anaemia. Gut 1983;24:1141-7.

6 Carmel R. Prevalence of undiagnosed pernicious anemia in the elderly. Arch Intern Med 1996;156:1097-100

7 Toh BH, van Driel IR, Gleeson PA. Pernicious anemia. N Engl J Med 1997:337:1441-8.

8 Heatley RV, Wyatt JI. Gastritis and duodenitis. In: Haubrich W, Schaffner S, Beak F, eds. Bockus-Gastroenterology, 5th edn. Philadelphia: Saunders, 1994:635-55

9 Babior BM. The Megaloblastic Anemias. Hematology, 4th edn. New York: McGraw- Hill, 1990:453-81

10 Asaka M, Kimura T, Kudo M, et al. Relationship of Helicobacter pylori to serum pepsinogens in an asymptomatic Japanese population. Gastroenterology 1992;102:760-6.

11 Taylor DN, Blaser M. The epidemiology of Helicobacter pylori infection. Epidemiol Rev 1991;13:42-59.

12 Rollason TP, Stone J, Rhodes JM. Spiral organisms in endoscopic biopsies of the human stomachs. J Clin Pathol 1984;37:23-36.

13 Warren JR. Unidentified curved bacilli on gastric epithelium in active chronic gastritis. Lancet 1983;1:1273-5.

14 Claeys D, Faller G, Appelmelk BJ, et al. The gastric $\mathrm{H}_{+}, \mathrm{K}+$-ATPase is a major autoantigen in chronic Helicobacter pylori gastritis with body mucosa atrophy. Gastroenterology 1998;115:340-7.

15 Negrini R, Lisato L, Zanella I, et al. Helicobacter pylori infection induces antibodies cross-reacting with human gastric mucosa. Gastroenterology 1991:101:437-45

16 Negrini R, Savio A, Appelmelk BJ. Autoantibodies to gastric mucosa in Helicobacter pylori infection. Helicobacter 1997; (suppl 1):S13-16.

17 Fong TL, Dooley CP, Dehesa M, et al. Helicobacter pylori infection in pernicious anemia: a prospective controlled study. Gastroenterology $1991 ; 100: 328-32$

18 Gonzalez JD, Sancho FJ, Sainz S, et al. Campylobacter pylori and pernicious anaemia. Lancet 1988:1:57.

19 O'Connor HJ, Axon AT, Dixon MF. Campylobacter-like organisms unusual in type A (pernicious anaemia) gastritis. Lancet 1984;2:1091.

20 Kojima A, Taguchi O, Nishizuka Y. Experimental production of possible autoimmune gastritis followed by macrocytic anemia in athymic nude mice. Lab lnvest 1980:42:387-95.

21 Sakaguchi S, Fukuma K, Kuribayashi K, et al. Organ-specific autoimmune diseases induced in mice by elimination of T cell subset. I. Evidence for the active participation of T cells in natural self-tolerance; deficit of a T cell subset as a possible cause of autoimmune disease. $J$ Exp Med 1985;161:72-87.

22 Nishio A, Hosono M, Watanabe $Y$, et al. A conserved epitope on $\mathrm{H}+, \mathrm{K}(+)$-adenosine triphosphatase of parietal cells discerned by a murine gastritogenic T-cell clone. Gastroenterology 1994;107:1408-14.

23 Nishio A, Katakai T, Hosono $M$, et al. Breakdown of self-tolerance by intrathymic injection of a T-cell line inducing autoimmune gastritis in mice. Immunology 1995;85:270-5.

24 Watanabe T, Tada M, Nagai H, et al. Helicobacter pylori infection induces gastric cancer in mongolian gerbils. Gastroenterology 1998:115:642-8.

25 Oshima C, Okazaki K, Matsushima Y, et al. Induction of follicular gastritis following postthymectomy autoimmune gastritis in Helicobacter pylori-infected BALB/c mice. Infect Immun 2000;68:100-6.

26 Fukuma K, Sakaguchi S, Kuribayashi K, et al. Immunologic and clinical studies on murine experimental autoimmune gastritis induced by neonatal thymectomy. Gastroenterology 1988;94:274-83

27 Sakagami T, Dixon M, O'Rourke J, et al. Atrophic gastric changes in both Helicobacter felis and Helicobacter pylori infected mice are host dependent and separate from antral gastritis. Gut 1996;39:639-48

28 Judd LM, Gleeson PA, Toh BH, et al. Autoimmune gastritis results in disruption of gastric epithelial cell development. Am J Physiol 1999. 277:G209-18.

29 Berson SA, Yalow RS. Radioimmunoassay of gastrin. Gastroenterology 1970;58:1-14

30 McGuigan JE. Immunochemical studies with synthetic human gastrin Gastroenterology 1968;54:1005-11

31 Heid CA, Stevens J, Livak KJ, et al. Real time quantitative PCR. Genome Res 1996;6:986-94

32 Appelmelk BJ, Faller G, Claeys D, et al. Bugs on trial: The case of Helicobacter pylori and autoimmunity. Immunol Today 1998;19:296-9.
33 Stolte $M$, Meier $E$, Meining $A$. Cure of autoimmune gastritis by Helicobacter pylori eradication in a 21 - year-old male. Z Gastroenterol 1998:36:641-3.

34 Aspinall GO, Monteiro MA. Lipopolysaccharides of Helicobacter pylori strains P466 and MO19: Structures of the $O$ antigen and core oligosaccharide regions. Biochemistry 1996;35:2498-504.

35 Aspinall GO, Monteiro MA, Pang $\mathrm{H}$, et al. Lipopolysaccharide of the Helicobacter pylori type strain NCTC 11637 (ATCC 43504): Structure of the $\mathrm{O}$ antigen chain and core oligosaccharide regions. Biochemistry 1996;35:2489-97.

36 Faller G, Steininger $\mathrm{H}$, Appelmelk B, et al. Evidence of novel pathogenic pathways for the formation of antigastric autoantibodies in Helicobacter pylori gastritis. J Clin Pathol 1998;51:244-5.

37 Ma JY, Borch K, Sjostrand SE, et al. Positive correlation between $\mathrm{H}, \mathrm{K}$-adenosine triphosphatase autoantibodies and Helicobacter pylori antibodies in patients with pernicious anemia. Scand J Gastroenterol 1994;29:961-5.

38 Haruma K, Komoto K, Kawaguchi $\mathrm{H}$, et al. Pernicious anemia and Helicobacter pylori infection in Japan: Evaluation in a country with a high prevalence of infection. Am J Gastroenterol 1995;90:1107-10.

39 Kojima A, Prehn RT. Genetic susceptibility to post-thymectomy autoimmune diseases in mice. Immunogenetics 1981;14:15-27.

40 Mori Y, Hosono M, Murakami K, et al. Genetic studies on experimental autoimmune gastritis induced by neonatal thymectomy using recombinant inbred strains between a high- incidence strain, $B A L B / c$, and a low-incidence strain, DBA/2. Clin Exp Immunol 1991;84:145-52.

41 Maaroos HI, Kekki M, Villako K, et al. The occurrence and extent of Helicobacter pylori colonization and antral and body gastritis profiles in an Estonian population sample. Scand J Gastroenterol 1990:25:1010-17.

42 Satoh K, Kimura K, Taniguchi Y, et al. Biopsy sites suitable for the diagnosis of Helicobacter pylori infection and the assessment of the extent of atrophic gastritis. Am J Gastroenterol 1998;93:569-73.

43 Alderuccio F, Toh BH, Tan SS, et al. An autoimmune disease with multiple molecular targets abrogated by the transgenic expression of a single autoantigen in the thymus. J Exp Med 1993;178:419-26.

44 van Doorn NE, Namavar F, Sparrius M, et al. Helicobacter pylori-associated gastritis in mice is host and strain specific. Infect Immune 1999:67:3040-6.

45 Barrett SP, Gleeson PA, de Silva H, et al. Interferon-gamma is required during the initiation of an organ-specific autoimmune disease. Eur $J$ Immunol 1996; 26: 1652-5.

46 Martinelli TM, van Driel IR, Alderuccio F, et al. Analysis of mononuclea cell infiltrate and cytokine production in murine autoimmune gastritis. Gastroenterology 1996;110:1791-802.

47 Bamford KB. Chronic gastrointestinal inflammation. Fems Immunol Med Microbiol 1999:24:161-8.

48 D'Elios MM, Manghetti M, De CM, et al. Thelper 1 effector cells specific for Helicobacter pylori in the gastric antrum of patients with peptic ulcer disease. J Immunol 1997;158:962-7.

49 D'Elios MM, Manghetti M, Almerigogna F, et al. Different cyłokine profile and antigen-specificity repertoire in Helicobacter pylori-specific T cell clones from the antrum of chronic gastritis patients with or without peptic ulcer. Eur J Immunol 1997; 27: 1751-5.

50 Karttunen R, Karttunen T, Ekre H-P, et al. Interferon gamma and interleukin 4 secreting cells in the gastric antrum in Helicobacter pylori positive and negative gastritis. Gut 1995;36:341-5

51 Mohammadi M, Czinn S, Redline R, et al. Helicobacter-specific cell-mediated immune responses display a predominant Th 1 phenotype and promote a delayed-type hypersensitivity response in the stomachs of mice. J Immunol 1996:156:4729-38.

52 Sawai N, Kita M, Kodama T, et al. Role of gamma interferon in Helicobacter pylori- induced gastric inflammatory responses in a mouse model. Infect Immun 1999;67:279-85.

53 Mohammadi M, Nedrud J, Redline R, et al. Murine CD4 T-cell response to Helicobacter infection: TH1 cells enhance gastritis and TH2 cells reduce bacterial load. Gastroenterology 1997;1 13:1848-57.

54 Saldinger PF, Porta $N$, Launois $P$, et al. Immunization of BALB/c mice with Helicobacter urease $B$ induces a T helper 2 response absent in Helicobacter infection. Gastroenterology 1998;115:891-7.

55 Fiorentino DF, Bond MW, Mosmann TR. Two types of mouse T helper cell. IV. Th2 clones secrete a factor that inhibits cytokine production by Thl clones. J Exp Med 1989;170:2081-95.

56 Uchida K, Okazaki K, Chiba T, et al. Analysis of cytokine in the early development of gastric secondary lymphoid follicles in Helicobacter pylori-infected BALB/c mice with neonatal thymectomy. Infect Immun 2001;69:6749-54

57 Fox JG, Beck P, Dangler CA, et al. Concurrent enteric helminth infection modulates inflammation and gastric immune responses and reduces Helicobacter-induced gastric atrophy. Nat Med 2000;6:536-42.

58 Lawrence DA. Transforming growth factor-beta: A general review. Eur Cytokine Netw 1996:7:363-74.

59 Czarniecki CW, Chiu HH, Wong GH, et al. Transforming growth factor beta 1 modulates the expression of class II histocompatibility antigens on human cells. J Immunol 1988;140:4217-23.

60 Palladino MA, Morris HF, Starnes HF, et al. The transforming growth factor-betas. A new family of immunoregulatory molecules. Ann NY Acad Sci 1990;593:181-7.

61 Chen Y, Kuchroo VK, Inobe J, et al. Regulatory T cell clones induced by oral tolerance: Suppression of autoimmune encephalomyelitis. Science 1994:265: 1237-40

62 Bellone G, Aste AM, Trinchieri G, et al. Regulation of NK cell functions by TGF- beta 1. J Immunol 1995;155:1066-73. 
63 Hunter CA, Bermudez L, Beernink H, et al. Transforming growth factor-beta inhibits interleukin-12-induced production of interferon-gamma by natural killer cells: A role for transforming growth factor-beta in the regulation of $\mathrm{T}$ cell-independent resistance to Toxoplasma gondii. Eur J Immunol 1995;25:994-1000.

64 Pardoux C, Asselin PC, Chehimi J, et al. Functional interaction between TGF-beta and IL-12 in human primary allogeneic cytotoxicity and proliferative response. J Immunol 1997;158:136-43.

65 Scharton KT, Afonso LC, Wysocka M, et al. IL-12 is required for natural killer cell activation and subsequent $\mathrm{T}$ helper 1 cell development in experimental leishmaniasis. J Immunol 1995; 154:5320-30.

66 Schmitt E, Germann T, Goedert S, et al. IL-9 production of naive CD4+ T cells depends on IL-2, is synergistically enhanced by a combination of TGF-beta and IL-4, and is inhibited by IFN-gamma. J Immunol 1994; 153:3989-96.
67 Johns LD, Flanders KC, Ranges GE, et al. Successful treatment of experimental allergic encephalomyelitis with transforming growth factor-beta 1. J Immunol 1991;147:1792-6.

68 Kuruvilla AP, Shah R, Hochwald GM, et al. Protective effect of transforming growth factor beta 1 on experimental autoimmune diseases in mice. Proc Natl Acad Sci U S A 1991;88:2918-21.

69 Racke MK, Sriram S, Carlino J, et al. Long-term treatment of chronic relapsing experimental allergic encephalomyelitis by transforming growth factor-beta 2. J Neuroimmunol 1993;46:175-83.

70 Lindholm C, Quiding-Jarbrink M, Lonroth $\mathrm{H}$, et al. Local cytokine response in Helicobacter pylori-infected subjects. Infect Immun 1998:66:5964-71.

71 Nakamura K, Kitani A, Strober W. Cell contact-dependent immunosuppression by CD4(+)CD25(+) regulatory T cells is mediated by cell surface-bound transforming growth factor beta. J Exp Med $2001 ; 194: 629-44$

\section{Pay per view}

For just $\$ 8$ you can purchase the full text of individual articles using our secure online ordering service. You will have access to the full text of the relevant article for 48 hours during which time you may download and print the pdf file for personal use.

\section{www.gutjnl.com}

